\title{
Laser Doppler measurements of cochlear blood flow during loud sound presentation
}

\author{
F.Scheibe ${ }^{1}$, H. Haupt ${ }^{1}$, A. L. Nuttall ${ }^{2}$, and C. Ludwig ${ }^{1}$ \\ ${ }^{1}$ ENT Department, Medical Center (Charité), Humboldt University, Berlin, German Democratic Republic \\ ${ }^{2}$ Kresge Hearing Research Institute, University of Michigan Medical School, Ann Arbor, MI 48109, USA
}

Received March 28, 1989 / Accepted April 12, 1989

Summary. The laser Doppler flowmeter may give responses to loud sound that reflect the vibration of cochlear structures rather than changes in cochlear blood flow. The present study demonstrates that the positive artifactual response (i.e., increased flow reading) to sound at frequencies above approximately $5 \mathrm{kHz}$ can be eliminated by using flowmeters which have electronic filters at 4 and $12 \mathrm{kHz}$, limiting the bandwidth of the optical Doppler shifted frequency range to lower frequencies. However, when using the $4 \mathrm{kHz}$ filter a "residual" immediate negative response to loud high-frequency sound $(10 \mathrm{kHz}$ tone at $125 \mathrm{~dB}$ SPL) is evident at the beginning of the exposure. These findings are discussed with regard to the suitability of the method for investigating the effect of sound/noise on cochlear blood flow.

Key words: Laser Doppler flowmetry - Cochlear blood flow - Sound exposure - Guinea pig

\section{Introduction}

Laser Doppler flowmetry is a relatively new method for the continuous measurement of cochlear microvascular hemodynamics and was introduced by Miller and others $[4,7,8,17,23]$. Although there is uncertainty about the particular vascular beds contributing to the measured flux value $[7,11,16,18,20]$, the method provides excellent information on the relative changes in cochlear blood cell flux in animal experiments under various experimental manipulations [e.g., 1, 2, 6, 12, 18]. However, it has been demonstrated that the laser Doppler flowmeter may give erroneous (i.e., non-flow related) responses during loud sound exposure. It has been shown that the artifact is derived from the sound-induced vibration of the cochlear structures [21]. This artifact can be avoided if the noise is turned off and measurements are made during the silent period [20]. However, this proce-

Offprint requests to: F. Scheibe, HNO-Klinik des Bereichs Medizin (Charité) der Humboldt-Universität, Schumannstrasse 20-21, DDR-1040 Berlin, German Democratic Republic dure does not permit the study of the immediate effect of noise on cochlear blood flow during exposure.

The Periflux flowmeter (Perimed, Sweden) used in the present study has two selectable upper frequency filters, limiting the measuring range of the optical laser Doppler signal to 4 or $12 \mathrm{kHz}$. The current study was devised to show the effect of the $4 \mathrm{kHz}$ filter on the artifactual response to loud sound at various frequencies. Previous studies in a guinea pig model have shown that high-frequency sound exposure stimulates the basal part of the cochlea, causing changes in local blood flow and oxygen tension $[5,13,14]$. Thus, the present study attempted to show the suitability of the laser Doppler method for investigating the effect of sound on cochlear blood flow.

\section{Materials and methods}

The experiments were performed on a total of 53 pigmented guinea pigs, weighing between 240 and $630 \mathrm{~g}$, with normal Preyer's reflex. The animals were anesthetized with $\alpha$-chloralose $(70 \mathrm{mg} / \mathrm{kg}$ body weight) and ethyl urethane $(415 \mathrm{mg} / \mathrm{kg}$ body weight) given intraperitonially. The animals were tracheotomized, paralyzed with gallamine triethiodide and artificially respirated, monitoring the end-expiratory $\mathrm{pCO}_{2}$. Body temperature was maintained at $38.0 \pm 0.2^{\circ} \mathrm{C}$. The carotid artery was cannulated to measure the systemic blood pressure and for the sampling whole arterial blood. The mean arterial blood pressure and the heart rate were recorded continuously. Arterial $\mathrm{pO}_{2}$ and acid-base status were determined before and after the experiment. The procedures used have already been described in detail [15].

The head of each animal was fixed using a moveable headholder. The cochlea was then exposed by a ventrolateral approach, leaving the ossicular chain and tympanic membrane intact, and the mucosa overlying the promontory was gently removed. Care was taken to keep the bone dry. Each animal was exposed unilaterally to sound in a closed-field system [22].

Blood flow was measured with the Periflux PF 2 laser Doppler flowmeter (Perimed KB, Stockholm, Sweden), using the special probe PF 103 (OD $2.2 \mathrm{~mm}$ ). The needle-shaped probe of the flowmeter was placed over the bone of the lateral wall of the basal and the apical part of the cochlea by means of a micromanipulator (Fig. 1), leaving a probe-to-bone distance of about $300 \mu \mathrm{m}$. The operating principle of the laser Doppler flowmeter has been described in detail elsewhere $[9,10,19]$. The output of the instrument - the blood cell flux - is proportional to the number and the 


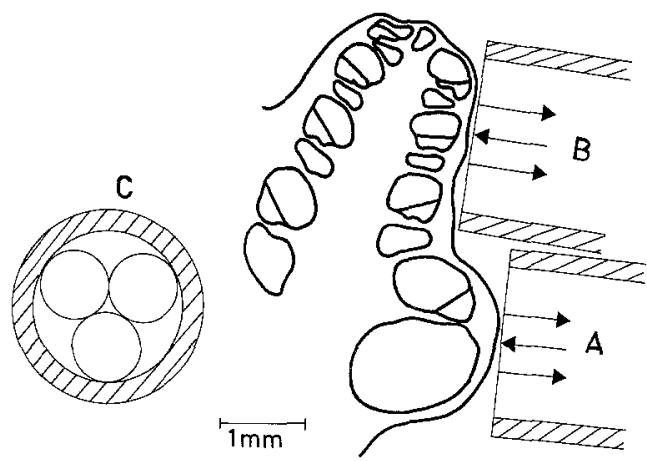

Fig. 1A-C. Schematic diagram showing the laser probe (OD 2.2 $\mathrm{mm}$ ) placed over the lateral wall of the basal $(\mathbf{A})$ and the apical (B) part of the guinea pig cochlea, and a cross-section $(\mathbf{C})$. Two probes are shown, illustrating the relative sizes of the probes and possible positions. Only one probe at one or the other position was used in actual experiments

mean velocity of the cells within the measured volume. The flowmeter has two selectable Doppler shift frequency ranges: $20 \mathrm{~Hz}-12 \mathrm{kHz}$ for high-perfused areas and $20 \mathrm{~Hz}-4 \mathrm{kHz}$ for lowperfused areas. According to the manufacturer's instructions, the two alternatives are to be tested. If the flux value is significantly higher with the $12 \mathrm{kHz}$ upper frequency filter, this latter one should be used. Accordingly, using both frequency ranges, measurements were made of normal cochlear blood flow and of dynamic changes, induced by the animals breathing a hypoxic gas mixture containing $8 \%$ oxygen in nitrogen for $5 \mathrm{~min}$ (three experiments). The efficiency of the $4 \mathrm{kHz}$ frequency filter in eliminating non-flow-related positive sound-induced laser signals was tested by measuring the response to loud pure tones at frequencies between 1 and $10 \mathrm{kHz}$ at $125 \mathrm{~dB}$ SPL in six live animals and in two animals 5-40 min post-mortem.

Using the $4 \mathrm{kHz}$ filter, the effect of a $10 \mathrm{kHz}$ tone at $125 \mathrm{~dB}$ SPL on the laser Doppler signal recorded from the basal part of the cochlea, the mean arterial blood pressure and the heart rate were investigated in 42 animals. The period of exposure lasted up to $1 \mathrm{~h}$. In order to test the response of the systemic blood flow to sound, the laser probe was additionally positioned over the neck muscles in three animals. Moreover, the total back-scattered value taken from pin 2 of the $\mathrm{J} 300$ connector at the rear panel of the flowmeter was measured in four of the animals before and during the sound exposure with the laser probe in the basal cochlear position. This value correlates with the red blood cell content within the tissue volume measured. To demonstrate the character of the spectral change in back-scattered laser light during sound presentation, the frequency spectrum of the primary, unprocessed Doppler signal was recorded in four live animals and in one of these animals within $8 \mathrm{~min}$ post-mortem before and during the exposure. The signal was taken from pin 5 of the $\mathrm{J} 300$ connector, using the terz-octav analyzer TOA 111 (VEB Messelektronik. Dresden, GDR) and the level recorder PSG 101 (VEB Messgerätewerk. Zwönitz, GDR).

\section{Results}

The animals tolerated the anesthesia, artificial respiration and surgery with the initial arterial blood pressure, heart rate and arterial acid-base status remaining within normal limits [15].

Since fluid accumulated on the bony surface of the cochlea, particularly during sound presentation in the chronic experiments, a certain distance between the tip of the laser probe and the cochlea was necessary for stable readings. About $300 \mu \mathrm{m}$ proved to be an appropriate distance between the probe and the bone. A larger gap (from approximately $500 \mu \mathrm{m}$ ) produced a slight decline in the laser Doppler output.

Using the $4 \mathrm{kHz}$ frequency filter of the flowmeter, the normal cochlear blood flow value was on average about $20 \%$ lower when compared with the $12 \mathrm{kHz}$ filter at the same gain setting. However, the relative change in the cochlear blood flow in the animals breathing a hypoxic gas mixture ( $8 \%$ oxygen in nitrogen) was found to be similar with both bandwidths (Fig. 2).

Exposure of the live animals to a $10 \mathrm{kHz}$ tone at $125 \mathrm{~dB}$ SPL resulted in an abrupt increase of the laser signal measured on the basal cochlear turn if the $12 \mathrm{kHz}$ filter was used (Fig. 3). This artifactual (i.e., non-flow related) response returned to the baseline just as rapidly when the sound was turned off. An artifact similar to that seen in the live animal occurred post-mortem, although the post-mortem response showed more varia-

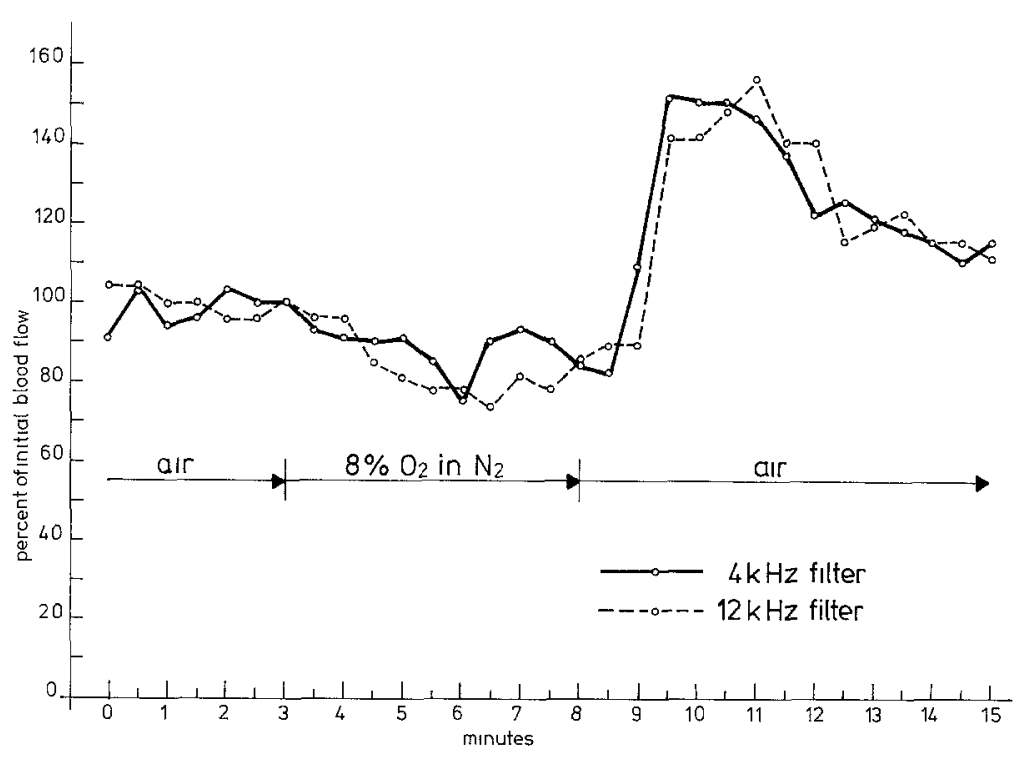

Fig. 2. Percent changes in the cochlear blood flow induced by having the animal breathe a hypoxic gas mixture of $8 \%$ oxygen in nitrogen for $5 \mathrm{~min}$. The flux value was recorded from the basal part of the cochlea by using the 4 and $12 \mathrm{kHz}$ filters of the flowmeter 


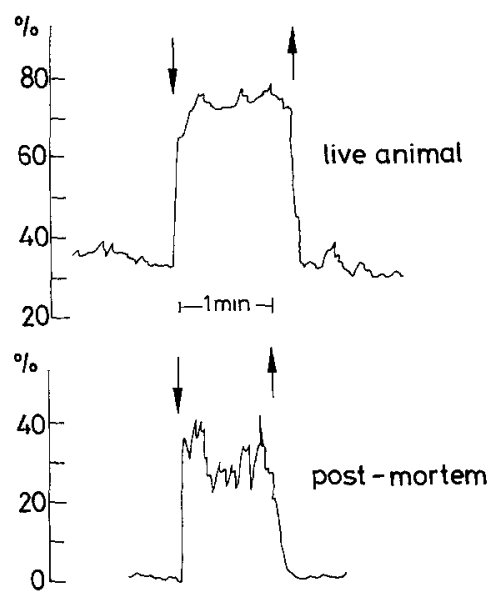

Fig. 3. Laser Doppler signal (\% scale reading) measured on the basal part of the cochlea in the live animal and post-mortem during exposure to a $10 \mathrm{kHz}$ tone at $125 \mathrm{~dB}$ SPL (between the arrows) with the $12 \mathrm{kHz}$ filter of the flowmeter (gain $\times 30$, time constant $3.0 \mathrm{~s})$

tion in its amplitude during exposure. All of these artifactual responses were found to be related to the intensity and the frequency of the sound as well as to the location of the probe on the cochlea. With probe positioning on the apical part of the cochlea, the lower the frequency, the higher the laser signal elicited. On the basal cochlear part, the high-frequency sound evoked a high artifactual response, but there was also a high artifact in response to a $1 \mathrm{kHz}$ tone, which was comparable in magnitude to that found with the $10 \mathrm{kHz}$ tone.

If the $4 \mathrm{kHz}$ filter was used, no positive response of the laser Doppler signal to the $10 \mathrm{kHz}$ tone at $125 \mathrm{~dB}$ SPL appeared in the live animal. The filter was effective in eliminating this artifactual response to loud $(125 \mathrm{~dB}$ SPL) pure tones down to a frequency of about $6 \mathrm{kHz}$. There was a low response to sound at $5 \mathrm{kHz}$, while tones at a frequency below $4 \mathrm{kHz}$ elicited high signals. However, with the $4 \mathrm{kHz}$ filter, a decrease in the basal cochlear laser signal became apparent at the beginning (up to $1 \mathrm{~min}$ ) of the exposure to a $10 \mathrm{kHz}$ tone at $125 \mathrm{~dB}$ SPL in about $90 \%$ of the animals (Fig. 4). The signal increased somewhat again when the sound was turned off, even after a 1-h period of exposure. In addition to these immediate responses, there was a further decrease in the signal during the lasting acoustic stimulation. The mean arterial blood pressure and the heart rate did not show sound-induced changes in about $70 \%$ of the animals. In about $30 \%$ of the animals, there was a transient decrease in the blood pressure and the heart rate at the beginning of the exposure (Fig. 5). In these animals also, a transient sound-induced decrease was observed in the systemic laser Doppler signal measured in the tissue of the neck muscles. Positioning the laser probe on the basal part of the cochlea, the total back-scattered value (taken from pin 2 of the $\mathrm{J} 300$ connector) did not change during the exposure.

In contrast to the findings in the live animal, an increase in the basal cochlear laser Doppler signal became evident post-mortem during the loud sound presentation $(10 \mathrm{kHz}$ tone at $125 \mathrm{~dB}$ SPL) despite using the $4 \mathrm{kHz}$ fil-

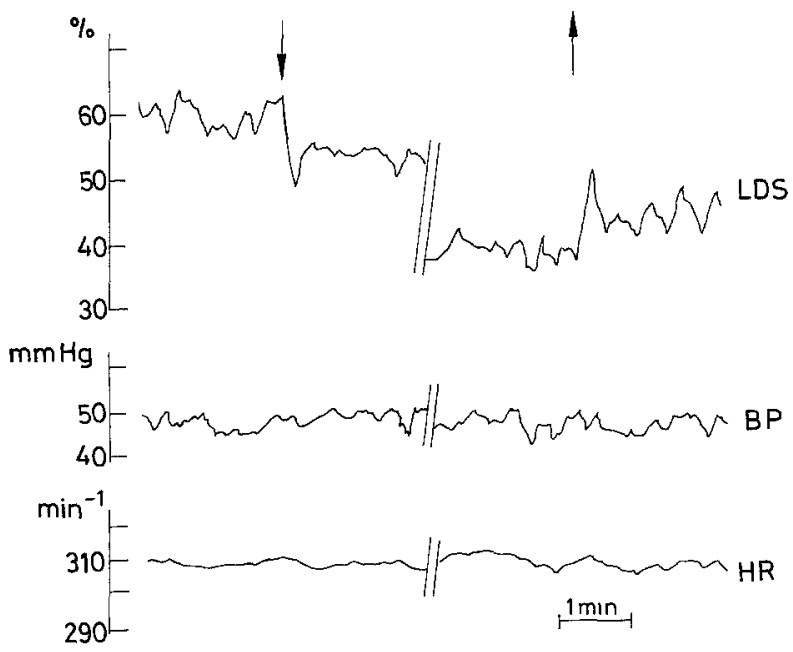

Fig.4. Laser Doppler signal (LDS), mean arterial blood pressure (BP) and heart rate (HR) in the live animal during exposure to a pure tone of $10 \mathrm{kHz}$ at $125 \mathrm{~dB}$ SPL for $1 \mathrm{~h}$ (between the arrows). The laser Doppler output was recorded from the basal part of the cochlea using the $4 \mathrm{kHz}$ filter of the flowmeter (gain $\times 10$, time constant $3.0 \mathrm{~s}$ )

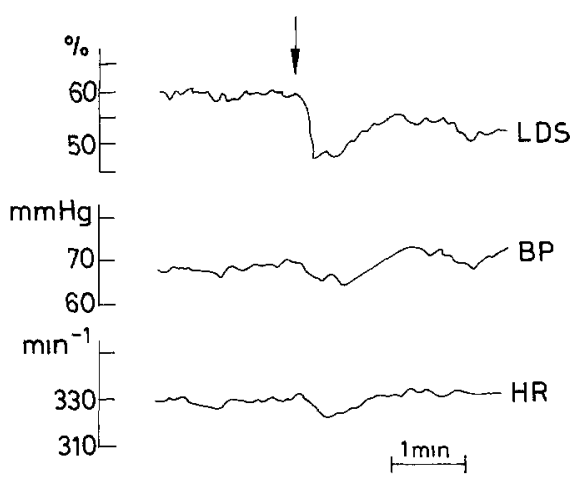

Fig. 5. Laser Doppler signal (LDS), mean arterial blood pressure (BP) and heart rate (HR) in a live animal during onset of exposure to a $10 \mathrm{kHz}$ pure tone at $125 \mathrm{~dB}$ SPL (arrow). The laser Doppler output was recorded from the basal part of the cochlea with the $4 \mathrm{kHz}$ filter of the flowmeter (gain $\times 30$, time constant $3.0 \mathrm{~s}$ )

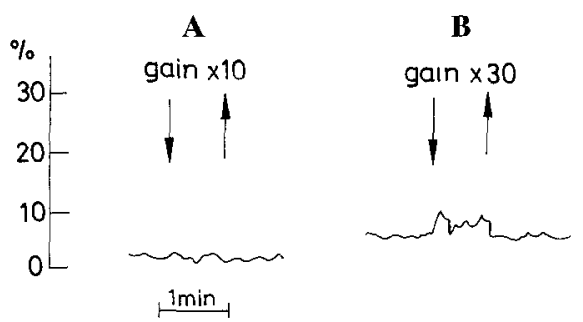

Fig. 6A, B. Laser Doppler signal (\% scale reading) measured on the basal part of the cochlea post-mortem during exposure to a $10 \mathrm{kHz}$ pure tone at $125 \mathrm{~dB}$ SPL (between the arrows) using the $4 \mathrm{kHz}$ filter and the gain setting (A) $\times 10$ and (B) $\times 30$ of the flowmeter (time constant $3.0 \mathrm{~s}$ )

ter (Fig. 6). The magnitude of the increase seen depended on the gain setting used.

Figure $7 \mathrm{~A}$ and $\mathrm{B}$ shows the frequency spectrum of the primary, unprocessed laser Doppler signal (pin 5) recorded from the basal cochlear part (A) in a live animal and (B) post-mortem (the same animal) before and dur- 


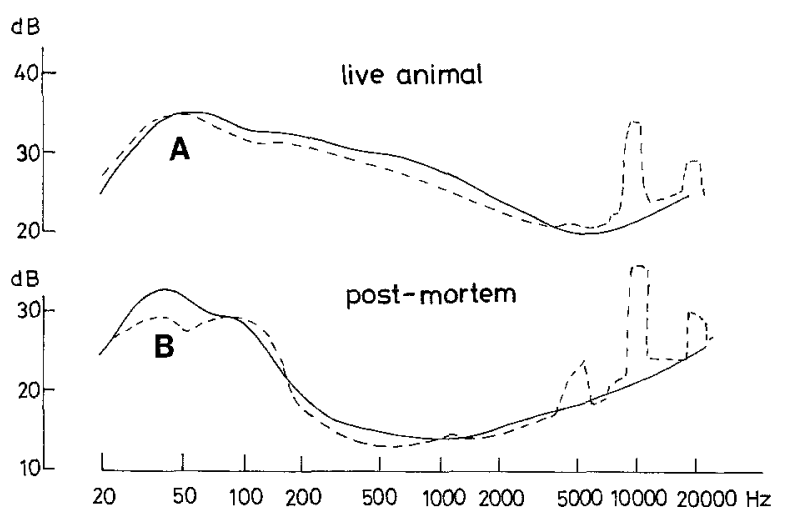

Fig. 7A, B. Frequency spectrum of the primary, unprocessed laser Doppler signal measured on the basal part of the cochlea $(\mathbf{A})$ in the live animal and (B) post-mortem before (continuous lines) and during (dotted lines) exposure to a $10 \mathrm{kHz}$ pure tone at $125 \mathrm{~dB} \mathrm{SPL}$

ing exposure to a $10 \mathrm{kHz}$ tone at $125 \mathrm{~dB}$ SPL. During the exposure to sound, the spectrum found in the live animal had a clear peak at the stimulus frequency of $10 \mathrm{kHz}$, while the spectral energy below $4 \mathrm{kHz}$ was lower compared to that before sound. The frequency spectrum post-mortem showed more variation and an additional peak occurred at about $5 \mathrm{kHz}$.

\section{Discussion}

According to the Doppler operating principle, the flowmeter responds not only to moving blood cells but also to all movements of defined structures relative to its probe head. This causes problems for the study of dynamic changes in the cochlear flow during sound presentation. It has been demonstrated recently that the laser Doppler flowmeter may give responses that are derived from the vibration of cochlear structures during acoustic stimulation [21]. The response also occurred in animals post-mortem and even in those with low hematocrits. This response was found to be tonotopic and was attributed to amplitude modultion of the backscattered laser light. The presence of such an artifactual (i.e., non-flow related) response to loud sound has been confirmed with the Periflux PF 2 laser Doppler flowmeter and the probe PF 103 (OD $2.2 \mathrm{~mm}$ ) used in the present study (Fig. 3). The tonotopic character of the artifact, however, only manifested itself when the probe was in an apical position, while the probe in a basal location elicited a high response following low-frequency sound $(1 \mathrm{kHz})$. This high basal turn output could possibly be due to the low-frequency response of the basilar membrane [3]. When comparing our present findings with a previous report by Thorne et al. [21] it should be realized that the probes differed in diameter, light guide geometry, exact placement on the cochlear basal locations, and that different types and models of flowmeters were used.

As shown in the present study, the positive artifactual response to loud sound at frequencies above $5 \mathrm{kHz}$ could be eliminated with the $4 \mathrm{kHz}$ filter of the Periflux instrument in the live animal. In this connection, the question arises to what extent the $4 \mathrm{kHz}$ filter diminishes the actual blood flow value, as compared to the $12 \mathrm{kHz}$ filter. While the normal cochlear flux value was found to be on average about $20 \%$ lower, the hypoxia-induced decrease in the cochlear blood flow and even the subsequent high flow increase was found to be similar with the two frequency ranges (Fig. 2). Although these changes in blood flow were not caused by sound, the similar findings suggest that the $4 \mathrm{kHz}$ filter can be used to assess relative changes in cochlear perfusion without substantially reducing the sensitivity of the instrument. This result is in line with the general observation made for skin that, as a rule, the true blood flow signal in low-perfused tissues is limited to a few $\mathrm{kHz}$ [19]. Thus, due to the selectable upper band frequency filters, the Periflux flowmeter seems to be useful for investigating basal cochlear hemodynamics during high-frequency sound presentations.

As demonstrated in Fig. 4, the $4 \mathrm{kHz}$ filter resulted in a drop in the cochlear laser signal which appeared immediately at the beginning of the acoustic stimulation $(10 \mathrm{kHz}$ tone at $125 \mathrm{~dB}$ SPL). Even after a further decrease in the course of a 1-h period of exposure, the signal again elevates somewhat, again occurring just as rapidly after offset of the sound. The question arises whether this immediate drop actually reflects a reduction in the cochlear blood flow, e.g., by vasoconstriction and/or a negative non-flow related artifact associated with a change in spectral energy in back-scattered light due to amplitude modulation with the sound-induced vibration of the cochlear structures [21]. The frequency spectrum of the unprocessed laser signal shows that the high-frequency amplitude modulated component is eliminated by using the $4 \mathrm{kHz}$ filter (Fig. 7A), and the spectral energy below $4 \mathrm{kHz}$ is lower compared to that before sound.

A previous report by Thorne et al. [21] noted the above data on the source of the amplitude modulated component and concluded that the vibration of the otic capsule was the source of the laser light modulation. In unpublished studies, we have re-evaluated this issue and now draw a different conclusion. Our evaluation was accomplished by comparing the displacement level of the vibration of a loudspeaker cone resulting in a reading of a Perimed PF 1 flowmeter to the actual level of vibration present on the surface of the cochlea. The vibrating loudspeaker cone caused a just observable flowmeter response when the displacement was about $1.5 \mathrm{~nm}$ at $10 \mathrm{kHz}$. The flowmeter frequency filter was set at $12 \mathrm{kHz}$. Under these conditions, which included no actual flow, a $10 \mathrm{kHz}$ amplitude modulated component was clearly evident in the "raw" signal frequency spectrum. In contrast, the surface vibration of a point location on the cochlear first turn and another point on the third turn both had vibration levels less than $0.5 \mathrm{~nm}$ with $105 \mathrm{~dB}$ SPL pure tone at $10 \mathrm{kHz}$. The surface measurements were made possible by using a Polytec model OFV 1000 laser vibrometer (Polytec GmbH, Waldbronn, FRG) and the derived Doppler signal was measured using a lock-in amplifier. Point measurements at the two sites studied in the cochlea showed the same topographic vibration pattern. Both locations exhibited a 
broader tuned function with a maximum response at $9 \mathrm{kHz}$. Equally high amplitude levels of $9 \mathrm{kHz}$ vibration were also noted on the medial wall of the bulla, on the bulla near the round window, and much more strongly near the tympanic ring. The low level of vibration of the otic capsule (below that which activates an "apparent" flowmeter reading in the no flow condition) combinded with the lack of match between the topographic aspect of the flow artifact and the actual vibrational topography of the cochlea now suggests that the "artifactual" flowmeter response to sound comes from within the cochlea.

The systemic parameters of blood pressure, heart rate and neck muscle perfusion showed a transient decrease in only some of the animals at the beginning of the exposure. Thus, the immediate drop in the cochlear laser signal may not be systemically related. Moreover, the unchanged total back-scattered value (pin 2), which is correlated to the blood cell content, is not compatible with a cochlear vasoconstriction. It is possible that this value might be less sensitive, since it also includes other optical variables. Finally. the findings obtained in our post-mortem animals fail to support an interpretation of an immediate sound-induced vasoconstriction in vivo. A positive laser response to the $10 \mathrm{kHz}$ pure tone $(125 \mathrm{~dB}$ SPL) occurred despite using the $4 \mathrm{kHz}$ filter (Fig. 6). Thus, the spectral change in the back-scattered light (Fig. 7B) seems to reflect a change in the sound-induced vibration of the cochlear structures post-mortem.

Because of uncertainty about the source of the immediate drop in the cochlear laser Doppler signal, measurements with the $4 \mathrm{kHz}$ filter during high-frequency sound presentation should only be made for pursuing the trend in cochlear blood flow in the course of the exposure period. In order to quantify the effect of sound on cochlear blood flow, the signals before and after the exposure should be compared or the sound must be turned off at frequent intervals and measurements then made in the silent interval [20]. These approaches provide that changes in blood flow during the quiet period reflect those during the exposure. Still, the effect of interrupted exposure on the cochlear blood flow may differ from that of continuous exposure. Nevertheless, for studying the effect of low-frequency sound or wide-band noise on cochlear perfusion as well as when flowmeters without selectable frequency filters are used, one of the two possibilities mentioned above should be chosen, depending on the particular aim of the investigation. Our present findings have shown that laser Doppler flowmetry used in such a way can be a valuable method for investigating the effect of sound or noise on the cochlear blood flow.

\section{References}

1. Dengerink HA, Wright JW, Miller JM, Goodwin P (1985) The effects of nicotine on laser Doppler measures of cochlear blood flow. Hear Res 20:31-36

2. Fechter LD, Thorne PR, Nuttall AL (1987) Effects of carbon monoxide on cochlear electrophysiology and blood flow. Hear Res 27:37-45
3. Flanagan JL (1962) Models for approximating basilar membrane displacement. II. Effects of middle-ear transmission and some relations between subjective and physiological behavior. Bell System Tech J 41:959-1009

4. Goodwin PC. Miller JM. Dengerink HA, Wright JW, Axelsson A (1984) The laser Doppler: a non-invasive measure of cochlear blood flow. Acta Otolaryngol (Stockh) 98:403-412

5. Haupt H, Scheibe F, Ludwig C (1988) Oxygen tension in the perilymph of sound-exposed guinea pigs. In: Loebe L-P, Lotz P (eds) VIII International Cochlea Symposium 1987. MartinLuther-Universität, Wiss. Beiträge 1988/15 (R 104), Halle (Saale), pp 93-95

6. Hultcrantz E, Nuttall AL (1987) Effect of hemodilution on cochlear blood flow measured by laser Doppler flowmetry. Am J Otolaryngol 8:16-22

7. Miller JM, Marks NJ, Goodwin PC (1983) Laser Doppler measurements of cochlear blood flow. Hear Res 11:385-394

8. Miller JM, Goodwin PC, Marks NJ (1984) Inner ear blood flow measured with a laser Doppler system. Arch Otolaryngol $110: 305-308$

9. Nilsson GE (1984) Signal processor for laser Doppler tissue flowmeters. Med Biol Eng Comput 22:343-348

10. Nilsson GE, Tenland T, Öberg PA (1980) Evaluation of a laser Doppler flowmeter for measurement of tissue blood flow. IEEE Trans Biomed Eng 27:597-604

11. Nuttall AL (1987) Techniques for the observation and measurement of red blood cell velocity in vessels of the guinea pig cochlea. Hear Res 27:111-119

12. Nuttall AL, Hultcrantz E, Larsen H-C, Angelborg C (1988) Cochlear blood flow increases after systemic hemodilution: comparison of simultaneous laser Doppler flowmetry and radioactive microsphere measurements. Hear Res 34:215-224

13. Scheibe F, Haupt H, Ludwig C (1986) Perilymphatic oxygen tension and cochlear blood flow in guinea pigs exposed to loud sound. Abstract 23th Workshop on Inner Ear Biology, Berlin, GDR. ENT Dept. (Charité), Humboldt Univ., Berlin, p 46

14. Scheibe F, Haupt H, Ludwig C (1988) Laser Doppler Measurement of cochlear blood flow during sound exposure. In: Loebe L-P, Lotz P (eds) VIII International Cochlea Symposium 1987. Martin-Luther-Universität, Wiss. Beiträge 1988/ 15 (R 104) Halle (Saale), pp 87-89

15. Scheibe F, Ludwig C, Haupt H, Flemming B (1989) Physiologische Parameter des Meerschweinchens unter Langzeitnarkose mit kontrollierter Beatmung. Z Versuchstierkd 32:25-31

16. Scheibe F, Haupt H, Berndt H, Magnus S, Weymar P (1990) Laser light transmission and laser Doppler blood flow measurements on the human, rat and guinea pig cochlea. Arch Otorhinolaryngol 247:20-23

17. Short OS, Goodwin PC, Kaplan JN, Miller JM (1985) Measuring cochlear blood flow by laser Doppler spectroscopy. Otolaryngol Head Neck Surg 93:786-793

18. Sillman JS, LaRouere MJ, Nuttall AL, Lawrence M, Miller JM (1988) Recent advances in cochlear blood flow measurements. Ann Otol Rhinol Laryngol 97:1-8

19. Tenland T (1982) On laser Doppler flowmetry. Methods and microvascular applications. Thesis, Linkóping University, Linköping

20. Thorne PR, Nuttall AL (1987) Laser Doppler measurements of cochlear blood flow during loud sound exposure in the guinea pig. Hear Res 27:1-10

21. Thorne PR, Nuttall AL. Scheibe F, Miller JM (1987) Soundinduced artifact in cochlear blood flow measurements using the laser Doppler flowmeter. Hear Res 31:229-234

22. Wagner H, Berndt H, Gerhardt H-J (1974) Zur Erzeugung kalibrierter Schallpegel am Trommelfell des Meerschweinchens. Arch Otorhinolaryngol 206:283-292

23. Wright JW, Dengerink HA, Miller JM, Goodwin PC (1985) Potential role of angiotensin II in noise-induced increases in inner ear blood flow. Hear Res 17:41-46 